This is the pre-peer reviewed version of the following article 'Slippery Slope Arguments', forthcoming at the Philosophy Compass.

\title{
Slippery Slope Arguments
}

\begin{abstract}
Slippery Slope Arguments are frequently dismissed as fallacious or weak arguments but are nevertheless commonly used in political and bioethical debates. This paper gives an overview of different variants of the argument commonly found in the literature and addresses their argumentative strength and the interrelations between them. The most common variant, the empirical slippery slope argument, predicts that if we do A, at some point the highly undesirable B will follow. I discuss both the question which factors affect likelihood of slippage and the relation between the strength of the prediction and the justificatory power of the argument.
\end{abstract}

\section{Introduction}

The slippery slope argument (henceforth SSA) is a staple in applied ethics, political discussion and legal decision making. Most frequently, the SSA takes the form of an empirical prediction, which warns of bad consequences if a certain course of action is taken. Here are some examples: If we allow voluntary euthanasia, people will end up performing non-voluntary and involuntary euthanasia(Callahan) If we allow pre-implantation diagnostics, we will end up practicing eugenics (Jachertz). This type of argument is frequently dismissed as scare-mongering or even fallacious, but this criticism is not justified for all SSAs. More recently, there has been a lot of research classifying subtypes of SSAs, explicating how these work and what their respective strengths and weaknesses are. Legal scholars have tended to take SSAs more seriously than moral philosophers, a phenomenon which this paper addresses. As the following discussion shows, SSAs are too varied for it to be possible to come to a general verdict regarding their strength. But a good understanding of the subtypes and the claims they make will enable us evaluate the SSAs that are put forward in moral and legal contexts case by case. While a plethora of different subtypes of SSAs have been distinguished (cf. (Walton), a central distinction is that between logical and empirical SSAs (Glover). These are often combined in hybrid SSAs, nevertheless, the underlying argument 
types are very different: one is an empirical prediction, the other an argument for a relevant similarity between two different cases.

\section{Logical Slippery Slope Arguments}

So called logical or reasonable grounds SSAs are not concerned with the likely effects of making a moral or legal decision, but with the question what the decision to take a certain step A commits us to. Two variants of this logical slippery slope argument are commonly identified in the literature, the no-principled distinction argument and the soritical SSA: The former draws a straightforward analogy between two types of cases: if we allow A, there is no good reason not to allow B because they are equivalent in their morally relevant properties (van der Burg; den Hartogh). Normally, this argument is used to counsel against the starting point of the slippery slope. An example for this kind of case is (Keown) argument against euthanasia (2002): he argues that the principles which justify voluntary euthanasia also justify non-voluntary euthanasia, for cases where people are unable to consent to such a killing. His reasoning as reconstructed by Jones 2010 (Jones) is that voluntary euthanasia already presupposes a judgment on the doctor's part that the patient in question would be better off dead. This judgment would then be sufficient to justify killing patients who are no longer in a position to give an opinion on whether or not they desire death. In essence, this type of argument attempts to show that two cases considered to be morally different are analogous in morally relevant ways. Therefore, the wrongness of B implies the wrongness of A;

alternatively, the permissibility of A implies that of B. As one philosopher's modus ponens is the other's modus tollens, either conclusion is in principle possible. The more common use of such a no-principled distinction argument is to argue against the starting point of the slope on the basis that the principles licensing its acceptance would also license the endpoint. But arguments from the permissibility of A to that of B are also sometimes found, for example in the enhancement debate. It is sometimes argued that as we already attempt to enhance cognitive performance by such means as improved teaching methods and small class sizes there is no good reason not to allow other forms of cognitive enhancement which directly target the brain. (Merkel) It is debatable whether it is appropriate to call logical SSAs 'slippery slope arguments' rather than simply classifying them as no-principled distinction arguments (van der Burg) or arguments from consistency, but the fact remains that they often constitute an important ingredient or supposition in a slippery slope argument. 
A second version of the logical argument is the soritical slippery slope argument. Here, it is argued that while A may be unobjectionable, "there is no relevant difference between $\mathrm{A}$ and $\mathrm{m}$, and $\mathrm{m}$ and $\mathrm{n}, \ldots \mathrm{y}$ and $\mathrm{z}$, and $\mathrm{z}$ and $\mathrm{B}$, and therefore, allowing $\mathrm{A}$ will in the end imply the acceptance of B"( (van der Burg) 44). The problem here is a version of the sorites or problem of the heap. It arises in the presence of vagueness, when there is no distinct cut off point at which an action clearly stops being morally permissible and starts being morally objectionable. The argument can be reconstructed as follows:

A is acceptable

For any member $A_{i}$ in the series from $A$ to $B$, if $A_{i}$ is acceptable, so is $A_{i+1}$

$\mathrm{B}$ is the final member of the series.

$\mathrm{B}$ is acceptable

It is possible to move from A to B in incremental steps and reach the conclusion that $\mathrm{B}$, too, must be acceptable if $\mathrm{A}$ is. Conversely, it is also possible to construct an argument which moves from the unacceptability of B to that of A in a stepwise process.

Sorites style slippery slope arguments have not only been employed in ethics but also in theoretical philosophy (J. Fodor and E. Lepore; J. A. Fodor and E. LePore). However, at least in theoretical philosophy, employing a sorites as an argument has been met with some perplexity. (Block) The fact that for vague concepts, no clear cut off point can be determined where one further step changes something from being $F$ (for example hairy) to being $G$ (for example being bald) and the resulting sorites paradox have generated a large body of literature concerned with the best interpretation of the problem and its solution. (See for example (Williamson)) However, concluding that we should accept that everything is $F$ (or, for that matter, $G$ ) and that there is no difference between being bald and having a head full of hair is not generally considered a viable solution.

The mere fact that the relevant qualities for moral assessment between A and B share a vague boundary does not imply that there is no underlying difference we can point to in order to justify why A should be permitted and B should not. Vagueness at the boundaries is insufficient to establish the equivalence of two categories at the beginning and endpoint of a continuum. At most, the inference which can be drawn is that there are some cases along the continuum for which the decision regarding their moral status will be somewhat arbitrary. A frequently cited example here are speed limits. A speed limit of $28 \mathrm{mph}$ or $32 \mathrm{mph}$ might be just as good in terms of lives saved as one of 30, but this arbitrariness does not matter as long as the speed limit is in the right ball park. (Cf. (Lode) 1999, citing (Glover) 1977) So while 
the sorites slippery slope highlights a real problem, which is finding a place to draw the line between acceptable and inacceptable action types, taken on its own it does not show that the action types at the beginning and the end of the slope are morally equivalent. There is therefore widespread agreement that sorites style SSAs are indeed invalid. (See for example (Walton; Govier; Lode)

So far, we have been discussing logical SSAs in their pure form. But more often than not, logical slippery slope arguments appear as part of an empirical SSA which predicts a certain development. In these cases predictions of future developments are based on the existence of some related logical SSAs. While the latter is sometimes also endorsed, this need not be the case. To support the empirical SSA, it is sufficient to argue that the start and endpoint may be perceived as sufficiently similar for slippage to occur or that a change for the worse may come about via a series of decisions, each of which appears justified by its similarity to a previous decision (Rizzo and Whitman; Williams).

\section{Empirical Slippery Slope Arguments}

Empirical slippery slope arguments are consequentialist arguments which focus on the bad results which are thought to ensue if a certain course of action is taken. The starting point itself is frequently held to be unproblematic or even morally desirable considered on its own (Volokh; Douglas; den Hartogh; LaFollette) however, cf. (van der Burg; Lode)). In any case, the undesirability of the starting point should not enter as a premise in the argument, as the argumentative heft is supposed to come from the undesirability of the consequences. Objections to empirical SSAs can take issue either with the prediction itself, claiming that it is too speculative (Oakley and Cocking; Burgess) or, alternatively, argue that the evaluation of the endpoint that the argument presupposes is mistaken (Douglas; Corner, Hahn and Oaksford "The psychological mechanism of the slippery slope argument"). Assessments of empirical SSAs therefore need to assess the probability with which the predicted event can be expected to occur and whether the event's moral evaluation is correct.

\subsection{The Importance of the Characterization of the Endpoint}

One variant of the empirical slippery slope predicts that by stepping on the slippery slope, we set in motion a shift in our own values. The worry is that if we start doing A, we will at some point start doing and finding acceptable $\mathrm{B}$, which is in fact inacceptable. This type of 
argument can be found in the abortion and euthanasia debate in the shape of the following prediction: If we start taking human life in certain marginal cases, this will lead to a diminishing of the value accorded to human life more generally. ((Lamb; White) Arguments like this which predict a change in our values for the worse are somewhat odd conceptually, as has been pointed out forcefully by den Hartogh. They predict that we will become unable to draw a moral distinction between cases that we currently see as clearly different. But if we are currently able to see that A is acceptable and B is inacceptable, why should it seem plausible to us that we will lose this ability in the future? In other words, bracketing the issue whether this prediction is correct or not, why should it seem convincing to us? One possible explanation put forward by Hartogh and LaFollette is that normally these arguments are already implicitly committed to there being something wrong with the starting point of the slope itself. This would of course make the argument problematic, as it would presuppose what it aims to establish, i.e. that $\mathrm{A}$ is not permissible.

However, the fear that we ourselves or our successors may condone things which are, in fact, inacceptable (Williams 1995; Douglas 2010) is normally not the focus of empirical SSAs. More frequently, such arguments are raised in the context of legislative or judicial decision making; they warn us of a development whereby society either becomes restrictive in a way that is thought to be problematic (as in arguments about gun control, freedom of speech, surveillance or legislation pertaining to people's consumption behaviour) or overly permissive, such that behaviour which the person raising the argument views as morally inacceptable is legally permitted and frequently practiced - as can be seen in anti-same sex marriage arguments, the abortion debate and in other contexts (cf. Schauer 1985; Volokh 2003). These SSAs frequently rest on the assumption that others may want to move society in a certain direction and that if we give them an inch, they will take a mile. This version of the argument claims that as a consequence of stepping onto the slippery slope, society will develop in a way we don't want it to (Lode; Volokh). Volokh (2003) points out that the progun lobby may be perfectly justified in fearing that a certain decision, such as a law requiring guns to be registered, may give further leverage to people who favour gun control. Slippery Slope arguments are often raised in contexts where different values, such as personal freedom and public health or safety are in conflict. For example arguments against banning trans fat raise the concern that the ban constitutes a step towards restricting people's dietary choices and thereby their autonomy even further. 'Today trans fats, tomorrow hot dogs' ((Resnik)). The proponent of the slippery slope argument believes that legislators and pro-health 
lobbyists will err on the side of favouring the wrong set of values, in this case public health over personal freedom.

So in principle, we can distinguish between empirical SSAs which predict that our own values or the next generation's might change in a way that is bad and those which are concerned with what we may be forced to be put up with later if we take certain steps now. Sometimes we have pure cases of one or the other type of argument, for example Volokh (2007) discusses slippage which may arise solely from the distribution of people's existing preferences if they are aligned in such a way as to facilitate a slide down the slippery slope. (Cf Volokh's discussion of multi-peaked preferences.page no.)

However, most slippery slope arguments appeal both to a process of changing values or habituation and to forces within society which are actively trying to promote that change in values or at least a change in what is allowed and forbidden. Returning to the argument against euthanasia, it has been claimed that some people want to promote non-voluntary euthanasia because of the cost savings that would entail for a state's health system and that this kind of procedure will become more acceptable to people once they have got used to the idea of voluntary euthanasia.( Lamb) Objections to infringements on civil liberties, also, frequently point to the fact that we take the status quo as normal and may not mind small restrictions being added: however, once we have gotten used to the new restriction, a further slight restriction might be introduced. In the end, so the thought, individuals will put up with restrictions they would never have accepted had they all been introduced at once.

Appeals to the pernicious effect of habituation often go hand in hand with appeals to similarity of adjacent cases and the impossibility of adequately distinguishing these. For example, Resnik supports his argument that there is a danger of moving from banning trans fats to banning other unhealthy fats and foods by pointing out that the distinction between foods and food additives is unclear, so that we could not draw a line by saying that only food additives may be banned. Slippery slopes that occur in judicial decision making also rely heavily on perceived similarity between cases; here, subsequent cases are treated similarly to a precedent but then also become precedents themselves, so that over time, judicial decisions move much further down the slippery slope than was initially intended (Von der Burg,(Schauer) Lode). 
More often than not, slippery slope arguments appeal to a mixture of factors such as habituation processes, problems in drawing distinctions and to social pressures in the direction of a slippery slope.

\subsection{Psychological factors facilitating slippage}

The psychological processes that empirical SSAs frequently appeal to are analogous to features we find in logical SSAs. In the latter, the claim is put forward that no principled distinction can be drawn, in the former, the claim that for contingent psychological reasons, different cases will not be distinguished. Developments such as the medicalization of certain conditions or the gradual acceptance of a ban of smoking in ever more locations show that such changes of attitude, sometimes for the better, sometimes for the worse, do frequently proceed in a gradual, stepwise fashion. This process is beautifully illustrated in an example Williams borrows from Goodman:

It is not merely that, at any given stage, there seem no adequate reasons to refuse the next step. In addition, it may well be that when a number of steps has been taken, the original objections to the process, or the degree of it, now seem misplaced. It is a mechanism very like that in terms of which Nelson Goodman explained the increasingly incompetent forgeries by van Meegeren were accepted as genuine Vermeers. Each new case was compared to a reference class that contained the earlier ones, and it was only when all the forgeries were bracketed, and the latest ones compared to a class of Vermeers free from van Meegerens, that it became obvious how awful they were. (p.132)

With hindsight, it is easy to show that and how a slippery slope event has taken place. The question is whether it is possible to give a more precise account of the mechanisms underlying changing attitudes, in order to assess how likely slippage actually is in a given case.

Recently, Corner et al. have tried to shed some light on these questions in a number of experiments. They conclude that people are able to distinguish between likely and unlikely developments and that the convincingness of slippery slope arguments is strongly dependent on how similar the starting point and the endpoint are perceived to be. They also try to explain the process of conceptual slippage predicted by such arguments, arguing that because our concepts are subject to exemplar based modification, changing the way we categorize one action type may indeed affect the categorization of other cases which are perceived as similar ((Corner, Hahn and Oaksford "The psychological mechanism of the slippery slope argument"; 
Corner, Hahn and Oaksford The Slippery Slope Argument: Probabilty, Utility and Category Boundary Re-appraisal) 2011, 2006). The result most relevant for present purposes is that participants' categorization judgments changed when they were told that cases similar to the one they had previously judged to fall into the category $-F$ were categorized as $F$. A significant number of participants would then reassign the exemplar they had formerly categorized as $-F$ to the category $F$. In the experiment, participants were asked to assess whether a particular region should be classified as an area deserving of Outstanding Natural Beauty status, basing their judgment on the number of species of Wild Animal living there. If they were subsequently told that an area with a similar number of wild animal species to the one they had categorized as not deserving of Outstanding Natural Beauty status had in fact been awarded this status, they were prone to re-categorizing their area as deserving the status too.

If this our moral categorizations are adjusted in a similar manner, this clearly supports the likelihood of a number of empirical SSAs. However, as the authors concede, there were relevant differences between the experimental setup which elicited re-categorizations and moral decision processes, as categories were assigned on the basis of numerical values (number of animal species), which allowed similarity to be measured quantitatively. Nevertheless, the fact that re-categorization takes place when participants are told about the status of similar cases is suggestive. It strengthens the claim that the moral decisions we make regarding A will affect our perception of the moral status of nearby cases. As the authors point out, arguments against the legalization of cannabis rely on such a mechanism when they argue that legalizing cannabis will lead to changes in the perception of other drugs. Of course, much will depend on how similar the two cases, in this example the two drugs, are perceived to be. In a further experiment, participants were asked to evaluate different SSAs considering the punishment of different types of crimes and the likely consequences of assigning crimes to specific punishment categories. Corner et al. were able to show that the more similar the beginning and the endpoint of the proposed development were, the more convincing participants perceived the arguments to be.

Corner et al. are optimistic that their research shows that we are able to tell good slippery slope arguments from bad ones. But there are complicating factors: First, similarity judgments are subjective, especially in moral questions. The perceived and actual likelihood of slippage can therefore come apart and arguably sometimes do. For example, some of the anti-gay marriage rhetoric relies on predicting incest or interspecies marriage as a consequence of 
allowing gay marriage. ((Council)Family Research Council) This strikes most of us as odd, as we can see lots of pertinent distinctions between interspecies marriage and gay marriage. However, if one views gay marriage as deeply unnatural, then the step to interspecies marriage may not seem that far. It is worth noting that these predictions may not seem farfetched to the people who make them. They may really think that these cases are relevantly similar and that therefore the predicted development is likely. What they lack is insight into other people's values and the distinctions others take to be obvious.

The fact that slippage seems so closely linked to similarity judgments also raises a problem for the justificatory power of such arguments: The more similar the two cases are perceived to be, the more likely it is that if B is seen as undesirable, so is A. This means that when a slippery slope argument is perceived as convincing, it is because we already perceive the two cases as analogous. But in this case, the objection that the more appropriate argument would be one addressing the wrongness of A resurfaces. While it is possible to be concerned both about $\mathrm{A}$ and about the fact that it might lead to $\mathrm{B}$, as a matter of intellectual honesty, one should then make one's objection to A taken by itself clear as well. The slippery slope argument would then be a further argument, not one that can be expected to stand on its own.

This criticism also applies to another psychological factor which is sometimes cited as relevant for SSAs, cognitive dissonance. Lode cites research by (Leippe and Eisenstadt) which shows that when subjects experience cognitive dissonance because they are asked to write an essay defending a position they do not in fact hold, the associated discomfort could be assuaged by changing their attitudes to bring them more in line with the essay they had written. Because it is associated with discomfort (Elliot and Devine), cognitive dissonance is supposed to aid slippage. In an effort to avoid this discomfort, we persuade ourselves that what we previously took to be problematic or inacceptable behaviour is in fact permissible. We are then likely to continue with such behaviour and find the next step down the slippery slope less objectionable. It thus appears that often the psychological factors presuppose that even at the beginning of the slope, we accept something we have previously taken to be wrong.

Even so, the scenario where the proponent of the argument sees A and B as having a different moral status but believes that slippage might occur because others are incapable of drawing the relevant distinctions remains a live option. Here, assumptions about others' perceptions of similarity are driving the argument. This argument may for example be applicable if it is known that some people are already explicitly committed to bringing about the endpoint of 
the slope and see that development as a natural continuation of step A. They may then take the permission of A as the first step in a device of stages, whereby they try to gradually make others accept further steps down the slope. (cf. (Enoch)

The possibility of conceptual slippage gives rise to a further possible objection to the empirical SSA. SSAs are normally premised on the assumption that we can tell that the endpoint of the slippery slope is bad and therefore to be avoided. Several authors (van der Burg 1991, Douglas 2010, Rizzo and Whitman 2003) raise the possibility that this judgment may be mistaken. Douglas argues that the more likely the predicted empirical development, the less likely it is that the endpoint is in fact bad. That a change of values may not always be for the worse can be seen in historical developments, such as that from moving to the abolishment of slavery to accepting interracial marriage. According to Douglas, the putative fact that future generations will believe that doing B is morally permissible is prima facie evidence in favor of the claim that it is in fact morally permissible. If this analysis is right, then the more likely a development, the less likely it is that the anticipated development is bad. This argument captures one of the insights from the psychological literature, which is that concept change is both perceived as more likely and de facto more likely where cases are already perceived as fairly similar. It may therefore apply to a small subset of arguments where we genuinely think the starting point is unproblematic and perceive the endpoint to be very similar. However, the argument fails to address what are arguably the most common forms of SSAs: Those where the proponent already has doubts about the starting point and those where we fear that people whose value systems already differ from ours may get their way (and for example, ban abortion).

In conclusion, psychological work on slippery slope arguments gives us a better understanding of the mechanisms of concept shift that influence both our assessment of these arguments and the likelihood of actual slippage. It also supports the points made earlier: frequently, we predict slippage because we already perceive cases to be similar or equivalent or because we think that others do.

\section{Some lessons}

A discussion of different variants of the SSA shows that some SSAs can indeed be dismissed as scare-mongering or fallacious, but this is by no means always appropriate. Frequently, slippery slope arguments are less than satisfactory because they are underdeveloped or rely 
heavily but covertly on objections to the first step onto the slope. To assess a specific slippery slope argument, we need to probe further into its explicit and implicit assumptions. This includes finding out whether the proponent really only objects to the endpoint of the slope or whether she has moral objections to the starting point as well. If the latter holds, it may well be that the core of the slippery slope argument is not an empirical prediction but a logical SSA which argues that there is no principled distinction between the starting point and the endpoint of the slope. If this is the case, then that is the argument which needs to be addressed.

An adequate assessment also needs to establish whether there are specific pressures within a society which make slippage more likely, for example in the trans fat case, if people are already actively lobbying for further bans of unhealthy foods. This means that the merits of each empirical SSA will have to be assessed case-by-case, and what counts as a refutation of an SSA will also vary. This is important, as counter-arguments against SSAs can, and sometimes do, miss the point of the argument they seek to refute. For example, if a certain development is predicted for a specific society, it is not sufficient as a rejection that this development has not taken place in other societies if these are different in ways relevant to the prediction (cf. Schauer 1985). Empirical SSAs almost always require an assessment which takes into account the cultural and political context in which the argument is put forward.

SSAs are frequently frustatingly vague and underspecified, and many would more usefully be put forward as slippery slope worries than as arguments. In this guise, they would serve the purpose of making us reflect commonalities between beginning and endpoint of the slope and social and psychological factors within a given society which make slippage likely or unlikely. The former is important for reaching a considered judgment regarding the starting point of a putative slippery slope (cf. Lode 1999). The latter is indispensable for an evaluation of the danger of slippage. An understanding of the varieties of slippery slope arguments is therefore a prerequisite for an informed judgment regarding specific arguments put forward.

Block, Ned. "Holism, mental and semantic." Routledge Encyclopedia of Philosophy Online. Ed. Craig, E. London: Routledge, 1998. Print.

Burgess, J A. "The Great Slippery Slope Argument." Journal of Medical Ethics 19 (1993): 169-74. Print. Callahan, Daniel. "When Self-Detertnination Runs Amok." Hastings Center Report 22.2 (1992): 52-55. Print. 
Corner, Adam, Ulrike Hahn, and Mike Oaksford. "The psychological mechanism of the slippery slope argument." Journal of Memory and Language 64.2 (2011): 133-52. Print.

Sun, R. and N. Myake eds. The Slippery Slope Argument: Probabilty, Utility and Category Boundary Re-appraisal. 2006. Cognitive Science Society. Print.

The Slippery Slope of Same-Sex Marriage. 2004.

den Hartogh, Govert. "The Slippery Slope Argument." A Companion to Bioethics. Wiley-Blackwell, 2010. 321-32. Print.

Douglas, Thomas. "Intertemporal disagreement and empirical slippery slope arguments." Utilitas 22.2 (2010): 184-97. Print.

Elliot, Andrew J., and Patricia G. Devine. "On the motivational nature of cognitive dissonance: Dissonance as psychological discomfort." Journal of Personality and Social Psychology 67.1994 (1994): 382-94. Print.

Enoch, David. "Once You Start Using Slippery Slope Arguments, You're on a Very Slippery Slope." Oxford Journal of Legal Studies 21.4 (2001): 629-47. Print.

Fodor, Jerry A., and Ernest LePore. Holism: A Shopper's Guide. Oxford: Blackwell, 1992. Print.

Fodor, Jerry, and Ernest Lepore. "Why Meaning (Probably) Isn't Conceptual Role*." Mind \& Language 6.4 (1991): 328-43. Print.

Glover, Jonathan. Causing Death and Saving Lives. London: Penguin, 1977. Print.

Govier, Trudy. "What's Wrong with Slippery Slope Arguments_." Canadian Journal of Philosophy XII.2 (1982): 303-16. Print.

Jachertz, Norbert. "Präimplantationsdiagnostik: Am Rande der schiefen Bahn." Dtsch Arztebl International 97.9 (2000): 507-. Print.

Jones, David Albert. "Is there a logical slippery slope from voluntary to nonvoluntary euthanasia?" Kennedy Institute of Ethics Journal 21.4 (2011): 379-404. Print.

Keown, John. Euthanasia, Ethics and Public Policy. Cambridge: Cambridge University Press, 2002. Print.

LaFollette, Hugh. "Living on a slippery slope." Journal of Ethics 9.3-4 (2005): 475 - 99. Print.

Lamb, David. Down the Slippery Slope - Arguing in Applied Ethics. Abingdon: Croom and Helm, 1988. Print.

Leippe, Michael R., and Donna Eisenstadt. "Generalization of dissonance reduction: Decreasing prejudice through induced compliance." Personality and Social Psychology 67 (1994): 395413. Print.

Lode, Eric. "Slippery Slope Arguments and Legal Reasoning." California Law Review 87.6 (1999): 1469543. Print.

Merkel, Reiner. "Mind Doping? Eingriffe ins Gehirn zur „Verbesserung" des Menschen: Normative Grundlagen und Grenzen." Der Neue Mensch? Enhancement und Genetik. Eds. Knoepffler, Nikolaus and Julian Savulescu. Freiburg, München: Alber, 2009. 177-212. Print.

Oakley, Justin, and Dean Cocking. "Consequentialism, Complacency, and Slippery Slope Arguments." Theoretical Medicine and Bioethics 26.3 (2005): 227-39. Print.

Resnik, David. "Trans Fat Bans and Human Freedom." The American Journal of Bioethics 10.3 (2010): 27-32. Print.

Rizzo, Mario, and Glen Whitman. "The Camel's Nose is in the Tent - Rules, Theories and Slippery Slopes." UCLA Law Review 51.2 (2003): 539-92. Print.

Schauer, Frederick. "Slippery Slopes." Harvard Law Review 99.2 (1985). Print.

van der Burg, Wibren. "The slippery slope argument." Ethics 102.1 (1991): 42-65. Print.

Volokh, Eugene. "Mechanisms of the Slippery Slope." Harvard Law Review 116 (2003): 1028-137. Print.

Walton, Douglas N. Slippery Slope Arguments. Oxford: Oxford University Press, 1992. Print.

White, David E. "Slippery slope arguments." Metaphilosophy 16.2-3 (1985): 206-13. Print.

Williams, Bernard. "Which Slopes are Slippery?" Making Sense of Humanity. Ed. Williams, Bernard: Cambridge University Press, 1995. Print.

Williamson, Timothy. Vagueness. London: Routledge, 1994. Print. 
